\title{
ADOLESCÊNCIA, VIOLÊNCIA E INVISIBILIDADE SOCIAL: UMA REVISÃO CRÍTICA A PARTIR DA HISTÓRIA DE SANDRO
}

ADOLESCENCE, VIOLENCE AND SOCIAL INVISIBILITY:A CRITICAL REVIEW FROM THE HISTORY OF SANDRO

Camila Almeida Kostulski', Patricia Matte Rodrigues², Patrícia Paraboniं ${ }^{3}$, Dorian Mônica Arpin ${ }^{4}$

RECEBIDO: 24/04/2017 | ACEITO: 15/10/2019

DOI: $10.5902 / 2317175826823$

\section{RESUMO}

Este artigo propõe uma reflexão sobre adolescência, violência e invisibilidade social. Para abordar o tema, parte-se da história de Sandro, retratada no documentário "Ônibus 174" e no filme "Última parada 174". Busca-se discutir aspectos que interferem na construção de identidade em adolescentes que não encontram no olhar do outro um sentido para sua existência. Assim, ao não se sentirem pertencentes à sociedade, podem sofrer um processo de invisibilidade social, que os leva, muitas vezes, a se reconhecerem e serem reconhecidos nas cenas de violência. Dessa forma, o texto tece uma reflexão sobre as implicações da sociedade para com esses adolescentes. Sandro representa um conjunto de adolescentes que encontram na violência uma forma e um sentido de expressar e viver a vida, seguramente, com consequências que não podem ser banalizadas.

Palavras- chave: Adolescentes; Violência; Problemas sociais; Ato infracional.

1 Psicóloga, Mestre em Psicologia pela Universidade Federal de Santa Maria (UFSM).

2 Psicóloga, Especialista em Sistema Público de Saúde pelo Programa de Residência Integrada em Sistema Público de Saúde da Universidade Federal de Santa Maria (UFSM), Mestre em Psicologia pela Universidade Federal de Santa (UFSM).

3 Pós-Doutoranda e Professora Colaboradora do Programa de Pós-Graduação em Psicologia da Universidade Federal de Santa Maria (UFSM). Bolsista Capes.

4 Docente do Curso de Psicologia e do Programa de Pós-Graduação em Psicologia da Universidade Federal de Santa Maria (UFSM). 


\section{ABSTRACT}

This article proposes to reflect upon adolescence, violence and social invisibility In order to approach the theme, it starts from Sandro' story, whose narrative is portrayed in the "Ônibus 174" documentary and, in the movie called "Última Parada 174. It aims to discussion the aspects that injures the identity construction on the adolescents who do not meet a sense for their existences in the other's looks, feeling apart from the society they live in. In the process of social invisibility, these adolescents often recognize themselves and are recognized by others through violence. In this way, the text builds a reflection upon the society implications with these adolescents. Sandro represents a group of adolescents that, in the position of being socially invisible, experience through violent acts one way, one path to express and live their lives, certainly with consequences that must not be minimized.

Keywords: Adolescents; Violence; Social issues; Infraction act.

\section{Introdução}

A adolescência consiste em um período de transição da infância para a idade adulta, representando para o adolescente um processo de distanciamento das formas de comportamento e privilégios típicos da infância. O adolescente passa por um processo no qual se vê convocado a reformular os conceitos que tem a respeito de si mesmo, que o levam a abandonar sua autoimagem infantil e a projetar-se no futuro (CORSO; CORSO, 2018).

O Brasil possui 25 milhões de adolescentes na faixa etária de 12 a 18 anos, o que representa cerca de $15 \%$ de sua população. Trata-se de um país marcado pela desigualdade social, acarretando em consequências diretas para a população infanto-juvenil (BRASIL, 2006). Os jovens são a parcela da população que tem o maior índice de mortes como resultado da violência, sendo que a maioria são negros, com idade entre 15 e 24 anos, pobres e do sexo masculino (SOARES, 2004). Além disso, o "Mapa da Violência 2015" aponta que os jovens são as maiores vítimas das mortes por armas de fogo no Brasil. Do total de 42.416 óbitos por disparo de armas de fogo em 2012, 24.882 foram de pessoas na faixa de 15 a 29 anos, o equivalente a $59 \%$. Os números de joven mortos por armas de fogo em 2012 são os mais altos já registrados pelo Mapa da Violência desde 1980 (WAISELFISZ, 2015)

Recentemente, a Fundação Abrinq (2018), traçou um cenário do panorama da infância e da adolescência no Brasil, compilando levantamentos importantes no país. Estes dados mostram que com relação à adolescência, em 2010, 3.936.869 era o número de pessoas de zero a 17 anos nas favelas; em 2015, 17,3 milhões se encontravam em situação de pobreza; e 5,8 milhões em situação de extrema pobreza. Em 2016, o número de denúncias ao disque 100 foi de mais de 144 mil dentre as pessoas de zero a 14 anos; no mesmo ano, o número de adolescentes de 15 a 17 anos trabalhando era de 1.292.311 no meio urbano, 352.448 no meio agrícola; e ainda em 2016, 17,5 dos nascidos (500.630) eram filhos de mães de até 19 anos (FUNDAÇÃo ABRINQ, 2018).
Tendo em vista esse panorama, o objetivo desse artigo é discutir alguns elementos referentes à violência e invisibilidade social vivida por adolescentes no Brasil. Para analisar e refletir sobre essas questões serão abordados alguns aspectos apresentados no documentário "Ônibus 174" de José Padilha (PADILHA, 2002) e no filme "Última parada 174" de Bruno Barreto (BARRETO, 2008). Ambos buscam retratar a história de vida de Sandro Barbosa do Nascimento, que, em 2000, sequestrou o ônibus 174, na cidade do Rio de Janeiro, caso que ganhou repercussão nacional e internacional.

Vale ressaltar que as ideias apresentadas nesse artigo não pretendem desresponsabilizar os adolescentes pelos atos infracionais que praticam, mas lançar alguma luz acerca do entendimento dos aspectos, multideterminados, que estariam na origem de tais atitudes e comportamentos violentos. É preciso atentar para o fato de que a indiferença, o não reconhecimento do outro enquanto ser humano, também pode se constituir uma forma de violência. Para a discussão que nos propomos neste artigo, primeiramente serão descritos, de forma sucinta, alguns aspectos abordados no documentário e no filme e, posteriormente, realizar-se-á uma articulação com a literatura que trata das temáticas da adolescência, violência e invisibilidade.

\section{Sandro Barbosa do Nascimento: uma história marcada pela violência}

Sandro nasceu em 07 de julho de 1988. Viveu com a mãe até os 8 anos de idade, contudo ainda quando estava sob os cuidados da mãe, já tinha vivência de rua. Ele presenciou a mãe ser assassinada a facadas em seu local de trabalho. Depois disso, Sandro residiu com sua tia por um tempo, mas certo dia saiu de casa e não voltou mais. Ele encontrou um grupo de meninos que "moravam" nas ruas do centro do Rio de Janeiro e passou a viver com eles. Sandro começou a usar drogas e a praticar furtos. Em 1993, ele testemunhou mais uma tragédia, a chacina da Candelária, situação de extrema violência muitos de seus "irmãos" de rua são brutalmente assassinados. Apesar disso, parece não ter recebido nenhuma atenção do Estado e/ou das autoridades, permanecendo "invisível" aos olhos da sociedade.

Devido ao seu envolvimento com as drogas e a prática de furtos, Sandro acabou cumprindo medidas socioeducativas. Ele passou pela instituição Padre Severino, que parece ter apresentado naquele momento, uma lógica punitiva e repressiva, portanto, em discordância com os preceitos do Estatuto da Criança e do Adolescente (BRASIL, 1990), no Art. 124, que dispõe em seu inciso $V$ que o adolescente deverá ser tratado com respeito e dignidade, assim como no inciso $X$ sobre a habitação em alojamento de modo que as condições sejam adequadas em termos de higiene e salubridade, aspectos que foram identificados como não presentes na história de internação de Sandro na re- 
ferida instituição. Importante ressaltar que em 2006, para superar práticas que limitam o adolescente ao ato infracional, foi criado o Sistema Nacional de Atendimento Socioeducativo (SINASE) que tem como um de seus princípios o respeito aos direitos humanos. Busca-se reconhecer um sujeito para além do ato, pertencente a uma coletividade que compartilha valores (BRASIL, 2006)

Diante de sua história e experiência de vida, Sandro parece não ter conseguido encontrar outro caminho que não o da violência. Assim, aos 21 ano de idade, em 12 de junho de 2000, ele sequestra o ônibus 174, na cidade do Rio de Janeiro, e, sob posse de um revólver, mantém várias pessoas reféns. As imagens do sequestro no documentário e no filme foram cedidas pela mídia que fez a cobertura do evento na ocasião. As imagens revelam que, inicialmente, Sandro não queria ser filmado, solicitando que a mídia se afastasse. Depois, parece ter entendido que a mídia poderia protegê-lo de alguma maneira. Ao relatar que seria um dos sobreviventes da chacina da Candelária talvez estivesse apelando a um outro olhar, ser visto não apenas como o sequestrador criminoso, mas também, vítima da violência e negligência da sociedade.

Neste episódio, Sandro apresenta a violência atuada, como também podemos reconhecer nosso papel enquanto sociedade diante dos jovens em situação de exclusão, violência, abandono e que cometem atos infracionais. Após horas de negociação com a polícia, Sandro saiu do ônibus utilizando uma das reféns como escudo humano. Um policial se aproxima e atira. $O$ disparo ating a refém e Sandro, talvez em um movimento reflexo, também acaba atirando contra a vítima. Ele é rendido pelos policiais, quase linchado pelas pessoas que acompanhavam o sequestro do ônibus e as negociações. Sandro foi conduzido para a viatura e acabou sendo assassinado, por asfixia, pelos policiais.

Assim, o desfecho da vida de Sandro tomou um rumo de proporções dramáticas. Como todo adolescente, Sandro tinha sonhos, mas seu fim foi selado ao entrar no ônibus 174, no dia 12 de junho de 2000. A história de Sandro reflete a de tantos outros jovens que vivem nas ruas, estando em situação de extrema pobreza, abandonados pela sociedade e pelo Estado.

\section{Adolescência e violência: a necessidade do olhar do outro,}

\section{condição de existência}

Conforme vimos, a violência parece ter marcado a vida de Sandro de forma definitiva, seja pela trágica morte da mãe e de seus "irmãos" de rua seja pela falta do olhar da sociedade diante de seu estado de desamparo e por último, o sequestro do ônibus que o levou à morte. A questão que se coloca diante desse quadro é: como se dá a travessia da adolescência quando vida está marcada por situações de violência, exclusão e invisibilidade social? E ainda, como se coloca a questão do futuro, do tornar-se adulto, nesse cenário?

O ponto de partida do processo de adolescência é fixado com a puberdade, por dados biológicos, mas isso não diminui a importância do fato de que o estatuto do jovem é tributário do olhar social e varia conforme a cultura e época (EMMANUELLI, 2008; ARPINI; WITT, 2015). Entendemos que uma das principais questões que se coloca para $o$ adolescente consiste na construção $e$ consolidação de sua identidade, ou seja, aquilo que configura sua existência através do reconhecimento e pertencimento ao laço social (CORSO; CORSO, 2018). Assim, a identidade é construída entre o individual e o social. Ela está sempre ligada a uma cultura, ao laço social, aos valores e as crenças que constituem o sujeito e são ao mesmo tempo por ele construídos. O reconhecimento demarca e nomeia o sujeito, não somente para os outros, mas também para si próprio (KEMPER, 2013). Entretanto, diante da falta de reconhecimento e de sua inscrição no social, as referências identitárias e, consequentemente, as possibilidades criativas de existência parecem ficar comprometidas (LESOURD, 2004; BROID, 2012; ROSA; VICENTIM, 2012).

A adolescência é uma época especialmente difícil da vida, sobretudo quando, somadas às questões relacionadas às vicissitudes da idade, se apresentam problemas relacionados à rejeição ou perda familiar, álcool, drogas, como também, de uma sociedade, muitas vezes, pouco acolhedora (ARPINI; WITT, 2015; BRASIL, 1990). Nesse contexto, a formação da identidade pode se constituir num processo penoso e complicado, considerando que ela é instaurada a partir do olhar do outro, na forma de um espelho. É na generosidade desse olhar que é construída a imagem de valor e às vezes, da significação humana (SOARES, 2004). A partir dessas colocações e da história de Sandro se faz necessário refletir sobre como essa identidade e existência se configuram no cenário da invisibilidade e exclusão social?

Diante disso, a invisibilidade de quem está excluído só é colocada em questão quando esses adolescentes acabam por perturbar a ordem social através da violência, do tráfico, do crime, passando, às vezes, mesmo que momentaneamente, à visibilidade (LESOURD, 2004). Além disso, esses atos de violência, criminalidade conferem ao adolescente, condição de poder, ainda que ilegítimo. A violência atribui poder a quem faz uso dela e provoca nos jovens o desejo de ser tão poderoso ou violento quanto os bandidos, muitas vezes admirados (KEHL, 2004; CORSO; CORSO, 2018). Os adolescentes podem buscar uma referência identificatória na imagem do criminoso - símbolo de potência que pode the conferir certa visibilidade (ZALUAR, 1994). No filme, mas também no documentário, os adolescentes retratados têm como referência as figuras do tráfico, da rua, as quais os ensinam que os limites e as regras são feitos por eles próprios e que "se quiser dinheiro tem que pegar e não pedir",fala do personagem Sandro em uma das cenas do filme "Última parada 174" de Bruno Barreto (BARRETO, 2008)

Em um estudo desenvolvido por Arpini e Gonçalves (2011), o qual aborda a violência do ponto de vista de adolescentes em situação de rua, as autoras apontam que o mundo das drogas parece ocupar um lugar onde se tem acesso a certo "poder", a certa "força", que imprime medo e possibilita o acesso a 
bens de consumo desejados e que, muitas vezes, não estão disponíveis para todos. Além disso, o contexto das drogas acaba sendo, para muitos jovens, a maneira de sobrevivência em um mundo desumano e excludente, sem o apoio da família e do Estado (ROSA, 2016). Em duas publicações recentes realizadas por Rizzini Carvalho e Couto (2017) e Rizzini e Couto (2018) a primeira de âmbito internacional e a segunda retratando estudos realizados no Brasil indicam a problemática das drogas e sua relação com a violência e com contextos de situação de rua, destacando a necessidade de compreender essas experiências de vida e de garantir que tenham participação ativa nas questões que dizem respeito as suas próprias vidas.

No entender de Marty (2006) o adolescente violento é, em muitos casos, uma pessoa desamparada, que necessita ter essa violência contida e canalizada por adultos que não sucumbam, que resistam à sua destrutividade e que sirvam de referência para ele. Porém, nossa sociedade tem apresentado certa dificuldade de se colocar como referência para os adolescentes. $O$ autor afirma ser necessário que a sociedade assuma o cuidado de seus adolescentes, que Ihes proporcione os recursos para seu futuro. Nesse mesmo sentido, segundo Gurski e Pereira (2016), ressalta que o futuro dos adolescentes não pode ser entregue a eles próprios, afinal eles atravessam um período da vida em que devem ser assistidos pelos adultos. Segundo o autor, depositar nas mãos de garotos e garotas o fardo de decidir quais os rumos morais ou sociais que de vem tomar é um sintoma da imobilidade e do sentimento de superfluidade correntes nos adultos de hoje.

A partir das colocações desses autores, entendemos que há a falta de referências mais consistentes para a construção da identidade nos adolescentes na atualidade. Muitos deles não contam com suas famílias, pois estas se encontram assoladas por problemas que muitas vezes envolvem questões semelhantes às deles, como álcool, drogas ou conflitos com a lei (BRONDANI; ARPINI, 2018) além do fato de que os pais se encontram muitas vezes perdidos quanto ao exercício de sua autoridade parental (CORSO; CORSO, 2018). Parece que na sociedade atual ninguém deseja ocupar o lugar de adulto, ninguém quer representar a lei diante das novas gerações (KEHL, 2004). Frustrar, proibir, dizer "não" e colocar limites exige que homens e mulheres sejam adultos (ocupem esse espaço) e ser adulto, parece ser sinônimo de careta, "chato" (CAMPOS, 2012).

Assim, muitos adolescentes ficam sem referência, sem parâmetros para organizar seu futuro. $\mathrm{Na}$ falta de referências familiares mais consistentes ou mesmo, como considera Rosa (1999), no apagamento do discurso familiar, prevalece o discurso social. Parece estar havendo certa desorientação nas referências básicas para uma construção identitária, o que geraria, dentre outros aspectos, desorientação quanto ao lugar a que pertencem esses adolescentes. Sandro, assim como vários outros adolescentes que vivem em situação de rua, parecem seres errantes, vagando pelas cidades em busca da sobrevivência. Nesse sentido, Broide (2012) tem advertido para a dificuldade de inscrição social dos jovens das periferias urbanas. Rosa (2016) também destaca o processo de invisibilidade que pode ser vivenciado por adolescentes que por seu lugar socioeconômico ou estético/lúdico tenderão a não serem reconhecidos pela sociedade. É importante destacar que, o que confere a existência psíquica seria, dentre outros aspectos, o olhar do outro, que atribuiria um lugar de reconhecimento (ROSA, 1999).

Assim, para muitos adolescentes, seu lugar na sociedade torna-se expressivo quando andam e circulam em grupos, pois seriam essas experiências em grupo que lhes asseguram um lugar. Segundo Arpini $(2003$, p. 70) "o grupo os torna "alguém" ao permitir que se tornem sujeitos de algo, mesmo que esse algo seja a violência". Para Soares (2004) impor-se através da violência pode ser visto como um grito de socorro de meninos e meninas até então invisíveis e que clamam por valorização e reconhecimento. Através do ato violento o adolescente muitas vezes, passa a ser visto, passa a ter algum reconhecimento, ainda que essa visibilidade dispare medidas punitivo/repressivas.

Esse aspecto também fora destacado por Winnicott (1979, p. 258), quando escreve que "a delinquência indica que certa esperança se mantém (...) o comportamento antissocial não passa, por vezes, de um S.O.S. para que a criança seja controlada por pessoas fortes, carinhosas e confiantes". Entendemos que essa situação não se aplica somente às crianças, mas também, no caso de Sandro ele poderia estar emitindo um pedido de socorro através de seus atos violentos e do uso de drogas. Entretanto, parece que um dos aspectos que teriam falhado em sua história teria sido justamente o reconhecimento dessa demanda de cuidado e contenção através do carinho, do olhar e da proteção de um outro.

Segundo Torossian et al. (2017), tal questão se constitui num desafio em nossa sociedade, que parece optar pela indiferença e exclusão dos jovens infratores, esquecendo que, por trás da prática do ato infracional, existe um adolescente que pode ter sua história de vida desconhecida e desconsiderada. A autora assinala que filmes como "Última Parada 174" parecem reproduzir o olhar da sociedade ao atribuir apenas aos adolescentes que cometem algum ato infracional a responsabilização pela violência e criminalidade, retirando desses adolescentes a condição de seres em desenvolvimento, que necessitam de cuidado e proteção.

A partir da história de Sandro, pode-se pensar em outros tantos adolescentes que vivem à margem da sociedade, excluídos e invisíveis. A questão que se coloca a partir dessas reflexões é a seguinte: o modo como a sociedade trata esses jovens, a partir da invisibilidade e indiferença não se constituiria numa forma de violência?

\section{Invisibilidade social e indiferença: a outra face da violência}

Sandro é um jovem negro, sem estudo, que se torna invisível nas ruas da cidade. E mais um menino de rua, entre tantos outros que não são "vistos" pela sociedade. Soares (2004) assinala que o mecanismo da invisibilidade é uma 
maneira que a sociedade encontra para proteger-se da culpa de poder usufruir dos pequenos prazeres diários sem pensar nos meninos que dormem ao relento. O autor assinala que a invisibilidade deriva principalmente do preconceito e da indiferença. $O$ preconceito anula a singularidade da pessoa, substituindo-a por uma imagem estereotipada, já a indiferença, na perspectiva do autor, provoca alto grau de sofrimento, produzindo efeitos na subjetividade.

Dessa forma, ao invés de vermos o adolescente "Sandro" ou "João" ou "Maria", vemos meninos perigosos, perdidos e desocupados. Somos tomados por nosso preconceito, e esquecemos que esses adolescentes têm histórias, que possuem características, qualidades e defeitos que estão muito além da classificação que lhes é imposta (SOARES, 2004; KEMPER, 2013; LESOURD, 2004). Esses estigmas têm consequências importantes para os processos identitários. Eles teriam a potencialidade de dissolver a identidade e em seu lugar construi uma imagem estereotipada (ZALUAR, 1994). Infelizmente, histórias como a de Sandro só ganham visibilidade quando alcançam situações violentas extremas, as quais atingem a sociedade dita de "bem".

Entendemos que o preconceito está associado à indiferença, pois, com esclarecem Moraes e Macedo (2011), a indiferença é vivenciada no encontro com o semelhante, é a marca do não reconhecimento daquilo que é mais próprio da singularidade do outro, ou seja, seu existir. Na concepção das autora a indiferença se faz presente nas situações de violência, pois se constitui como ausência de ajuda alheia. Não haveria investimento afetivo por parte do outro, fazendo deste modo, predominar um estado de desamparo, o qual pode ser atualizado em diversos momentos da vida. Essa dinâmica também atualizaria o dano psíquico decorrente da usurpação do direito de existir.

Neste mesmo sentido, Soares (2004) refere que há uma fome mais profunda que a fome física: a fome de sentido, de reconhecimento, fome de ser, que só é alcançada pelo olhar do outro que nos reconhece e valoriza. Parece que Sandro teria finalmente conquistado seu reconhecimento ao ser visto como um criminoso pelo país inteiro. Não que ele desejasse isso, mas foi oportunidade de se fazer conhecer e também de anunciar ao mundo que era um sobrevivente da chacina da Candelária. Enquanto vítima de uma situação de violência extrema, teria permanecido invisível aos olhos do mundo, mas enquanto criminoso, sequestrador, ganhou visibilidade.

Por algumas horas, Sandro chamou a atenção do país. Certamente essa reflexão não visa destituir a responsabilidade de Sandro com o ato violento, nem a possibilidade que cada um tem de decidir sobre seu destino. Lyra (2018), com seu testemunho de vida nos convoca a essa reflexão, afirmando que todos os aspectos assinalados como: fragilidades familiares, desigualdade social, educação de má qualidade, entre outros, certamente influenciam, mas não são determinantes. Contudo a intenção aqui é a de nos fazer analisar a nossa responsabilidade social diante dessa trajetória de Sandro. De uma sociedade que apenas "olha", por vezes com certo fascínio, a violência brutal divulgada nos meio de comunicação, apagando as histórias de sofrimento desses adolescentes que como Sandro, se encontram tão marcados pela violência e pelo abandono.

No caso de Sandro e de muitos outros adolescentes, o preconceito e a indiferença se confundem e refletem a invisibilidade social. Diante desse cenário, muitos acabam por buscar formas violentas de impor seu reconhecimento. Segundo Moraes e Macedo (2011), o si mesmo, quando capturado pela indiferença do semelhante atualiza efeitos de excesso e de fragilidade os quais acabam se expressando no que as autoras denominam de ato-dor. $O$ ato-dor é um recurso de sobrevivência psíquica, é colocar a dor psíquica de não existir para o semelhante na forma de ato. Muitas vezes esse ato comporta a mesma dose de violência experimentada diante da negação de seu existir. $O$ ato-dor revela o prejuízo instaurado nos registros da confiança. Nas palavras das autoras "as fraturas nas relações com os objetos, a desconfiança, o temor, a intolerância, o ataque, a inveja, a vingança, os ressentimentos atualizados não deixam dúvidas quanto à qualidade do que foi experienciado" (MORAES; MACEDO, 2011, p. 48).

Entendemos que o ato-dor, no caso de Sandro, está presente nos atos de violência praticados, os quais provavelmente constituem uma resposta à vivência da indiferença da qual fora vítima por parte da sociedade e do Estado, quando perde a mãe de maneira brutal e não recebe o acolhimento necessário, quando vai morar nas ruas e sua existência é mais uma vez negada, tendo que engendrar meios próprios para garanti-la e também diante da chacina da Candelária quando permanece na invisibilidade.

Entendemos que a violência que pode emergir daí, não tem uma relação de causa e efeito simples. Como parece ter sido retratado tanto no documentário quanto no filme, Sandro apresentava comportamentos violentos, entretanto, para além de projetar toda a culpa sobre ele, se faz necessário refletir sobre o papel da sociedade no desencadeamento desses atos. Não estaria a sociedade, através do preconceito, indiferença e invisibilidade, exercendo uma violência fundamental, no sentido de que negar a existência do semelhante é "não reconhecer" seu direito de ser e existir, de pertencer à humanidade, ao laço social?

Para Levisky (1997) a delinquência pode ser resultante de uma construção social cuja origem poderia estar na própria violência familiar e/ou social. A lógica da indiferença instaura o que o autor denomina de "violência passiva", a qual se expressa pela negligência, desfaçatez, corrupção, pelo fenômeno de fazer "vista grossa". Tais aspectos revelam um clima de conivência, reflexo da violência estrutural de nossa organização social e psicológica, com profunda desvalorização das relações humanas. Assim, ao invés de exercer a violência através da indiferença, é preciso reconhecer que ali existe um sujeito com tudo que isso implica e não (apenas) um delinquente, criminoso, assassino. É preciso reconhecer que há um sujeito, para que este seja responsabilizado pelos seus atos, mas também para que Ihe seja ofertado o tratamento necessário para provocar uma mudança subjetiva. 


\section{Considerações Finais}

Neste artigo tentamos estabelecer uma reflexão acerca da relação entre a vivência da adolescência e da violência no cenário da invisibilidade social. Certamente não pretendemos esgotar os questionamentos sobre essa temática, mas lançar alguma luz para avançar na compreensão da complexidade envolvida nessas situações.

$\mathrm{Na}$ figura de Sandro estão representados tantos outros meninos e meninas que se encontram na dura realidade das ruas, na luta pela sobrevivência, 0 que muitas vezes acaba por fazê-los adentrar no mundo das drogas e da violência. Tornam-se invisiveis para a sociedade, esquecidos pelo Estado, tratados com indiferença e preconceito, embora o que almejem seja o reconhecimento, aquilo que lhes aporta, através do olhar do semelhante/outro, a sua existência, aspecto fundamental para a constituição da identidade. Entretanto, diante da falta desse olhar, muitos acabam buscando o reconhecimento atravé das mais variadas formas de violência. Muitos deles apenas têm o sentimento de existência e pertencimento quando envolvidos com a criminalidade, a violência e as drogas.

A violência pode se manifestar por vários prismas, sendo que um deles comete-se ao desconsiderar o outro como semelhante, ou seja, quando torn o outro invisível, excluindo sua condição de ser desejante. Nesse sentido, entendemos que para reverter essa dura realidade é necessário que o Estado e a sociedade se façam presentes, como Lei, referência e limites. Faz-se fundamental propor ações sociais e políticas que trabalhem, além das consequên cias, a prevenção da violência na adolescência. Ainda, é preciso minimizar os estigmas e preconceitos, de forma que se consiga refletir sobre a adolescência seu papel e seu lugar na sociedade.

Nesse sentido, é importante reconhecer que as profundas desigualdades sociais no Brasil, certamente trazem atravessamentos nas histórias adolescentes. A partir da situação aqui apresentada, muitos adolescentes se encontram retratados, clamando por um olhar acolhedor da sociedade, por oportunidades e projetos nos quais possam ver-se inseridos. Por fim, uma das contribuições desse estudo, é dar visibilidade ao contexto dos adolescentes, não apenas a partir da situação violenta, mas problematizando o fato de que o autor de violência, pode ter sido antes uma vítima da violência, que não foi reconhecida, sendo alguém a quem não se deu oportunidade anterior.

Dar visibilidade é também uma forma de resistência, evitando minimizar a problemática, nos tirando da situação muitas vezes confortável, na qual o problema é colocado, ou seja, autores e vítimas como polos que não se interpenetram. Olhar para o problema, que por ser complexo não tem resposta rápida e pronta, é nos permitirmos uma implicação com nosso fazer e o sentido daquilo que fazemos.

\section{Referências Bibliográficas}

ARPINI, D. M. Violência e exclusão: adolescência em grupos populares. Bauru/SP : EDUSC, 2003.

ARPINI, D. M.; GONÇALVES, C. S. Drogas e álcool na relação com a violência: o Disponível em: http://revistaseletronicas.pucrs.br/ojs/index. php/revistapsico/article/ view/6443/7447' Acesso em: 20 out. 2016

ARPINI, D. M.; WITT, C. S. As múltiplas formas de ser adolescente. In: CAMPOS, H. R. SOUSA, S. M. G. Emocore: experiências grupais na constituição da
adolescência. Natal: EDUFRN; 2015. p. 11-28.

BARRETO, B. (Diretor). Última parada 174 [filme]. São Paulo: Paramount, 2008.

BRASIL. Lei n. 8.069, de 13 de julho de 1990. Dispõe sobre o Estatuto da Criança e do Adolescente e dá outras providências. Diário Oficial da União, Brasilia, DF, Seção 1,1990 .

BRASIL. Sistema Nacional de Atendimento Socioeducativo - Sinase. Brasília: Presidência da Republica, Secretaria Especial dos Direitos Humanos, Conselho Nacional dos Direitos da Criança e do Adolescente, 2006

BROIDE, J. Adolescência e violência: a criação de dispositivos clínicos no território conflagrado das periferias. In: GUSKI, R.; ROSA, M. D. POLI, M. C. Debates sobre a adolescência contemporânea e o laço social. Curitiba: Juruá, 2012, p. 123-136.

BRONDANI, R. P.; ARPINI, D. M. Experiências escolares de adolescentes em cumprimento de medida socioeducativa. Revista Educação PUC/Campinas, 24(1), 2019 p. 72-88.

CAMPOS, D. C. Saudade da família no futuro ou o futuro sem família? In: BAPTISTA, M. N.; Alegre: Artmed, 2012. p. 74-86.

CORSO, M.; CORSO, D. L. Adolescência em Cartaz: filmes e psicanálise para entendêla. Porto Alegre: Artmed, 2018

EMMANUELLI, M. A clínica da adolescência. In: CARDOSO, M. R.; MARTY, F. Destinos da adolescência. Rio de Janeiro: 7Letras, 2008. p. 17-38.

FUNDAÇÃO ABRINQ. Cenário da infância e adolescência no Brasil 2018. São Paulo, SP, 2018. Disponivel em: https://observatorio3setor.org.br/wp-ontent/
uploads/2018/04/cenario_da_infancia_2018_internet.pdf

GURSKI, R.; PEREIRA, M. R. A experiência e o tempo da passagem da adolescência contemporânea. Psicologia USP. São Paulo, v. 27, n. 3. 2016. p. 429-440.

KEHL, M. R. A juventude como sintoma da cultura. In: NOVAES, R.; VANNUCHI, P. Juventude e Sociedade: trabalho, educação, cultura e participação. São Paulo: Editora Fundação Perseu Abramo, 2004. p. 130-159.

KEMPER, M. L. C. Invisibilidade, identidade e laço social na contemporaneidade: sobre a exclusão nas esferas psiquica e social. Cadernos de psicanálise, 35(29), 2013. p.105-125. Disponivel em: http:///pepsic.bvsalud.org/scielo.php?.script=sci_ arttext\&pid=S1413-62952013000200007\&lng=pt\&tlng=pt Acesso em: 20 out. 2016

LESOURD, A. S. A construção adolescente do laço social. Petrópolis, RJ: Vozes, 2004

LEVISKY, D. L. Aspectos do processo de identificação do adolescente na sociedade contemporânea e suas relaçōes com a violência. In: LEVISKY, L. D. Adolescência e 1997. p. $17-30$ 
ADOLESCÊNCIA, VIOLÊNCIA E INVISIBILIDADE SOCIAL:

UMA REVISÃO CRÍTICA A PARTIR DA HISTÓRIA DE SANDRO

LYRA, E. Da favela para o mundo: não importa de onde você vem, mas para onde você vai. São Paulo: Buzz Editora, 2018.

MARTY, F. Adolescência, violência e sociedade. Ágora, 9(1):2006, 119-

131. Disponível em: http://www.scielo.br/scielo.php?script=sci_ arttext\&pid=S1516-14982006000100009 Acesso em: 20 out. 2016.

MORAES, E. G.; MACEDO, M. M. K. Vivência de indiferença: do trauma ao ato-dor. São Paulo: Casa do Psicólogo, 2011.

PADILHA, J. (Diretor). Ônibus 174 [DVD]. 133 min. Rio de Janeiro: Riofilme, 2002.

RIZZINI, I.; COUTO, R. M. B. População infantil e adolescente em situação de rua no Brasil: análises recentes. Rio de Janeiro/ CIESPI, 2018.

RIZZINI, I.; CARVALHO, T. \& COUTO, R. M. B. População infantil e adolescente em situação de rua: temas em destaque em âmbito internacional. Rio de Janeiro/ CIESPI, 2017.

ROSA, M. D. O discurso e o ato na produção do laço social: reflexões sobre a delinquência. Congresso Internacional de Psicanálise e suas Conexões - Trata-se uma Criança. Rio de Janeiro: Companhia de Freud, 1999. p. 275-287.

ROSA, M. D.; VICENTIM, M. C. Os intratáveis e o exílio do adolescente do laço social pelas noções de periculosidade e irrecuperabilidade. In: GUSKI, R.; ROSA, M. D.; POLI, M. C. Debates sobre a adolescência contemporânea e o laço social. Curitiba: Juruá, 2012, p. 39-57.

ROSA, M. D. A clínica psicanalítica em face da dimensão sociopolítica do sofrimento. São Paulo: Escuta/Fapesp, 2016.

SOARES, L. E. Juventude e violência no Brasil contemporâneo. In: NOVAES, R.; VANNUCHI, P. Juventude e Sociedade: trabalho, educação, cultura e participação. São Paulo: Editora Fundação Perseu Abramo, 2004. p. 89-114.

TOROSSIAN, S. et al. "Eu queria mudar": a psicanálise face a adolescência pobre e sem lugar. Subjetividades, Fortaleza, 17(3), 2017. p. 57-69.

WAISELFISZ, J. J. Mapa da Violência 2015-Mortes Matadas por armas de fogo. Brasília: Flacso Brasil; 2015. Disponível em: http://www.mapadaviolencia.org.br/pdf2015/ mapaViolencia2015.pdf Acesso em: 20 out. 2016.

WINNICOTT, D. W. Aspectos da delinquência juvenil. In: WINNICOTT, D. W. A criança e o seu mundo Rio de Janeiro: Zahar Ed, 1979. p. 256-261.

ZALUAR, A. Condomínio do Diabo. Rio de Janeiro: Revan, 1994. 